\title{
Intelligent buildings connected to future smart energy grids
}

\author{
L. Schibuola, M. Scarpa \& C. Tambani \\ University IUAV of Venice, Italy
}

\begin{abstract}
The spread of diffuse energy generation systems such as photovoltaics and combined heat and power generators will convert buildings from sole energy consumers into energy prosumers, i.e. energy producers and consumers. This will involve a much more dynamical interaction between buildings and the energy grid. As a consequence, electric distribution networks will be required to coordinate the energy draw/supply in order to optimize the use of renewable energy sources and preserve the reliability of the energy dispatch system, thus becoming smart grids. Smart grids will be able to act as coordinators of energy flows between diffuse energy producers and consumers, but buildings will be mainly managed in order to minimize their interaction with energy grids, thus minimizing the volatility of energy supply/draw, thus they will integrate energy management systems aimed at taking advantage of locally generated energy. In fact, buildings will be required to locally generate as much energy as possible, towards a Zero Energy Building perspective. For this purpose they will exploit technologies able to modulate energy demand and production by a suitable design of the building. So how will buildings, and consequently the related architecture, evolve in order to achieve these goals? In this paper the present status of the art as well as building configurations, procedures and energy management strategies able to ensure the best integration of typical residential and office buildings into smart grids are analysed.
\end{abstract}

Keywords: energy efficiency, smart grid, heat pump, HVAC management.

\section{Introduction}

The number of systems aimed at the generation of electricity starting from renewable (and unprogrammable) energy sources is growing as rapidly as the 
doubts about their full exploitability. In particular, the management of electricity generation from photovoltaics may be critical because of its intensity and concentration in time. As a matter of fact, photovoltaics is changing the market of electricity supply, since it allows mass production of electricity in time periods (the middle of the day) previously characterized by high electricity demand and, consequently, even by high prices. Some countries, and Italy among them, are now facing the relevant problem of the energy mix management in the middle hours of summer days, even if the total annual energy production is still within single-digit percentages (in Italy: $5.7 \%$ of the national electricity consumption and $6.5 \%$ of the national electricity generation, from data contained in [1]).

As a consequence, the whole electricity grid must be reformulated, moving from a top-down approach to a bottom-up one. This is the basic concept behind smart grids. As a matter of fact, smart grids may become the means able to fully exploit diffuse electricity generation, by the management of electricity generation and consumption among the prosumers (producers + consumers) connected with them. This way renewable energy sources will be better integrated and commended. The buildings connected to smart grids will be driven towards switching on/off deferrable loads or self-consuming the electricity locally generated, mainly by means of convenient electricity hourly prices, defined in a virtual market. Such a market is already active for large electricity users and producers, but it will be probably extended to users/producers acting at a smaller scale, down to domestic prosumers, as currently under study in some prototype applications. However, even in the case of a price-driven market for electricity exchange, the most favourable behaviour in building energy consumption/ generation would consist in total self-consumption of the generated electricity, in order to limit the need for energy management among the prosumers, in a perspective of pure Zero Energy Buildings, instead of Net Zero Energy Buildings. For this purpose, Germany, one of the largest markets for photovoltaics in the world, defined subsidies for the installation of batteries in conventional on-grid photovoltaic systems. As a matter of fact, the local consumption of electricity enabled by batteries would imply lower fluctuations in electricity demand and offer, thus ensuring a better energy balance, and consequently higher grid reliability and lower costs due to distribution infrastructures and losses.

In many countries dynamic electricity markets already exist. In Italy, for instance, Borsa Elettrica Italiana (BEI) has been active since April 2004 (De Martinis et al. [2]). It consists of two markets: the day-ahead market, defining the range of prices for the electricity traded at each hour of the following day, and the current day market, establishing the ultimate hourly prices for the electricity traded on the current day. BEI is coordinated by the national manager for energy markets (Gestore dei Mercati Energetici, GME), that defines the hourly prices of electricity by means of the marginal price mechanism. For each hour of the day under assessment, the marginal price mechanism cumulates the amount of electricity offered, in increasing price order, and the demanded electricity, in decreasing price order. The final price of the electricity is the one at which electricity demand and offer are matched, as illustrated by Figure 1. 


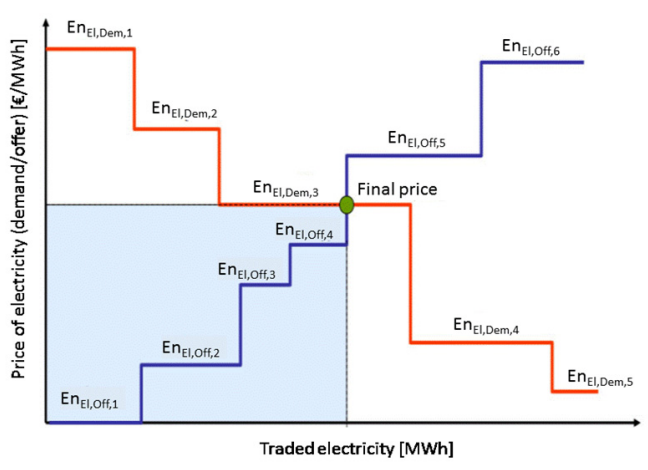

Figure 1: Example of application of the marginal price mechanism.

The profile of final hourly prices of the electricity may be interesting from various points of view. In this regard, Figure 2 is shown.

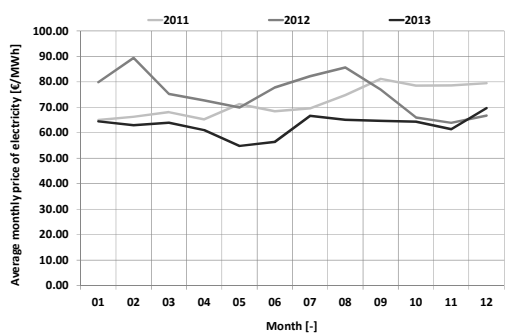

(a)

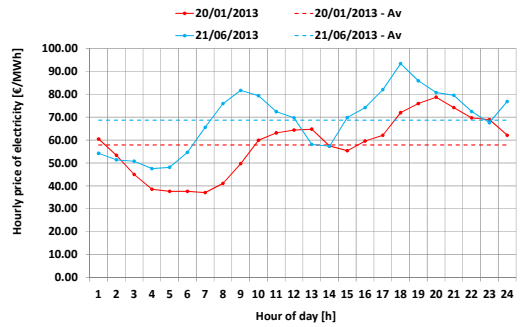

(b)

Figure 2: Profiles of prices of electricity in 2011, 2012 and 2013, in terms of average monthly values (a), and for two illustrative days, in terms of hourly values (b).

The profiles of the electricity prices in three years (2011, 2012 and 2013) and in two illustrative days show that the price of electricity, even if averaged on a monthly scale, is prone to large variations. Moreover, electricity prices are lower during midday hours, whereas some years ago, in the same period of the day, the highest prices took place instead. As a consequence, one could be interested in understanding whether buildings may take advantage from this market, concentrating the consumption of electricity in hours with low electricity prices or when the local photovoltaic system is generating electricity, for instance using heat pumps coupled with heat storages or harvesting electricity into the batteries of electric vehicles. Of course, in most countries only a few buildings involved in experimental projects can exchange electricity basing on a dynamic stock market. However, this seems to be the future and in many countries bi-directional electronic energy counters able to provide full communication between the 
building and the grid are being installed. Some experimental projects in Europe are walking along this path, in order to provide details about the expected reliability and technological feasibility of this approach. For instance, the smart grid in Bornholm (DK) [3], the smart grid in Gotland (SE) [4], as well as project Vattenfall [5] and remote heat pump management in Switzerland [6].

In particular, project Vattenfall gave the light to the "Smart Grid Ready" standard [7]. Heat pumps labelled according with standard "Smart Grid Ready" can be managed by the grid, basing on its needs to balance electricity offer and demand, through signals commanding forced switching on/off.

However, as a rule of thumb for the proper integration of buildings into smart grids, self-consumption of the generated electricity should be preferred, thus limiting potential energy imbalances for the grid. As a matter of fact, in a scenario characterized by the rapid growth of prosumer buildings, as implied by Directive 2010/31/EU (EPBD Recast) starting from 2021 for all new buildings, in case of mechanisms of electricity exchange governed by means of a pure market approach, power fluctuations may be relevant and hence destabilizing, and highly dependent on the reliability of the algorithms used for price assessment.

To sum up, in this paper, simulations are used to get the advantages behind advanced controls of heat pumps serving buildings provided with own photovoltaic systems and integrated into smart grids using dynamic fees for traded electricity.

In particular, in the simulations a typical apartment building was considered, and HVAC system control strategies and parameters were varied in order to calculate the levels of convenience achievable by means of conventional HVAC systems controlled by advanced strategies.

\section{Methods}

In this section the main hypotheses and boundary conditions behind the analysis performed are introduced, with particular focus on the simulation scheme and tools, the simulated building-plant system, and the considered control strategies.

\subsection{Simulation scheme and tools}

The following building energy simulations tools were used in order to perform the analyses contained in this paper:

- EnergyPlus: building energy simulation software developed by the U.S. Department of Energy. It is able to calculate both heating/cooling loads and HVAC system energy needs, but in the frame of this analysis it was used for the sole assessment of building heating/cooling loads, due to the lack of flexible control strategies on the HVAC system side.

- NXT: software aimed at the detailed simulation of advanced HVAC systems, developed at the University IUAV of Venice. This simulation code allowed the authors to perform simulations of HVAC systems governed by advanced strategies not available in common building energy simulation tools. 
The site chosen for the performed simulations is Milan. In particular, no Test Reference Year was used, but hourly weather data for specific year 2012, together with hourly electricity prices established in the same year by BEI. This way it is possible to associate weather conditions and actual electricity prices arising from the market.

To sum up, the calculation scheme is summarised in Figure 3.

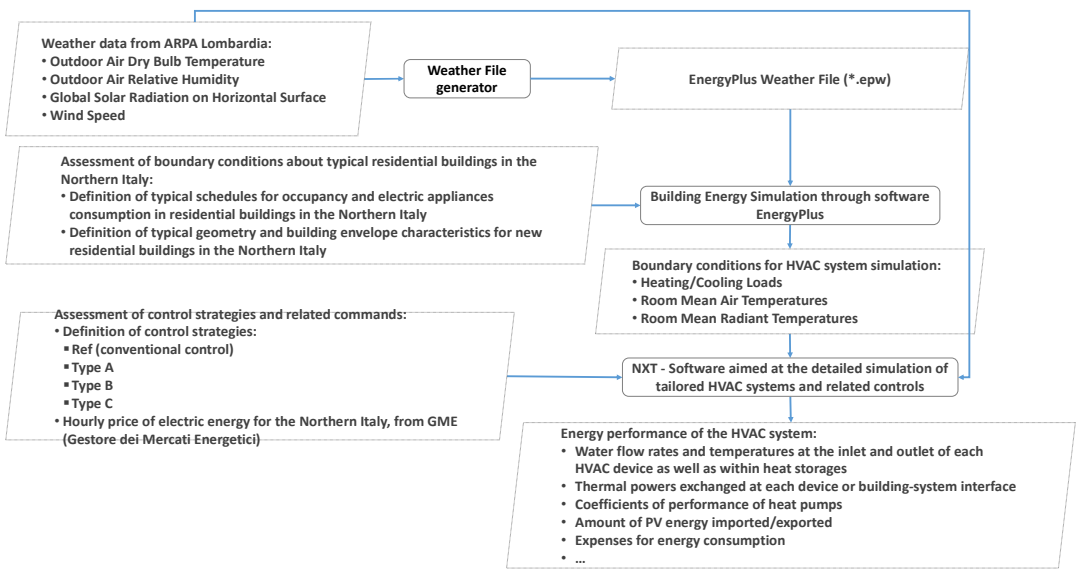

Figure 3: General calculation scheme behind the proposed analysis.

\subsection{Simulated building-plant system}

The simulated building consists of a three-floor apartment building, with two floors hosting apartments (in total, 8 apartments) and one floor for garages and warehouses, as shown in Figure 4.

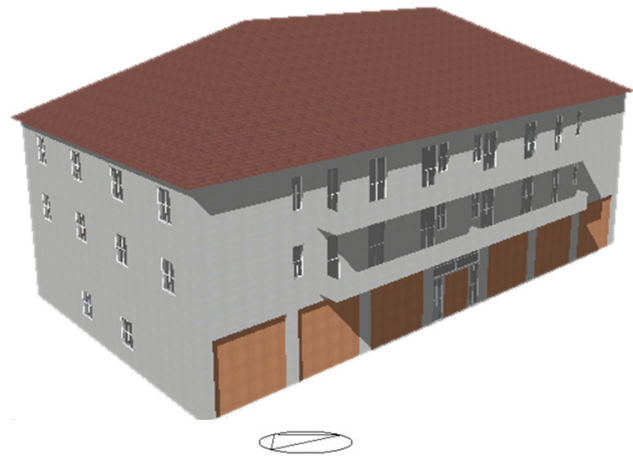

(a)

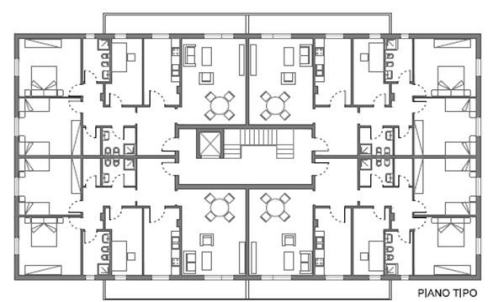

(b)

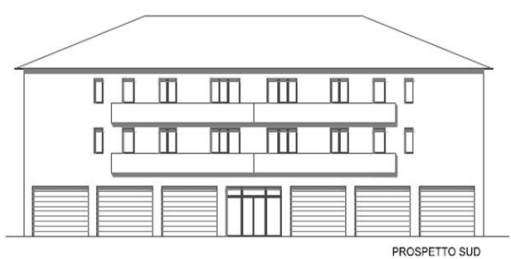

(c)

Figure 4: Shape of the simulated building. 
The covered area is equal to $517 \mathrm{~m}^{2}$, the heated volume is $2715 \mathrm{~m}^{3}$ and the envelope U-values are in agreement with Italian regulations implementing EPB Directive. Moreover, the following boundary conditions were assumed:

- Occupancy: 0.03 people $/ \mathrm{m}^{2}$ and typical profile for apartments, with average occupancy period equal to $16 \mathrm{~h} /$ day;

- Total internal heat gains for lighting and other electric appliances: maximum intensity equal to $8 \mathrm{~W} / \mathrm{m} 2$ and profile typical for apartment buildings, with a total energy amount equal to $84 \mathrm{Wh} /\left(\mathrm{m}^{2}\right.$.day);

- Infiltration and ventilation: $0.5 \mathrm{vol} / \mathrm{h}$ in garages and $0.3 \mathrm{vol} / \mathrm{h}$ for apartments. The resulting heating and cooling design capacities are equal to $18.4 \mathrm{~kW}$ and $21.1 \mathrm{~kW}$ respectively.

The HVAC generator consists of an inverter-driven heat pump feeding two water storages aimed at domestic hot water (DHW) supply (through a thermostatic mixing valve) and at heating/cooling purposes, through fan-coils. The heat pump is assisted by a solar water system sized to provide $70 \%$ of the yearly energy needs for DHW preparation.

Moreover, arrays of PV modules are integrated on the gable roof, on the side facing south. The PV modules, in mono-crystalline Silicon, have efficiency equal to $18 \%$ and cover a total area of $45 \mathrm{~m}^{2}$. The modification in electricity generation due to the photovoltaic cell temperature and the reflection of solar radiation due to the glass cover was calculated by software NXT on an hourly time step basis, whereas the total losses due to dirt deposition on PV modules, PV module mismatch as well as Joule effect through wires and inverter are summarised by means of a global efficiency value equal to $70 \%$ In this paper the PV system is intended to serve the sole heat pump. The electric power generated by the PV system is exported to the grid when the heat pump is in stand-by, whereas electric power is drawn from the grid when the amount of generated electric power is lower than the heat pump power consumption. Figure 5 shows the system described above.

\subsection{Considered control strategies}

The HVAC system described above underwent simulations performed varying relevant parameters, in particular the ones listed below:

- Domestic hot water storage: $50 \mathrm{l} /$ person and $100 \mathrm{l} /$ person

- HVAC water storage: $201 / \mathrm{kW}_{\text {Nominal }}$ and $401 / \mathrm{kW}_{\text {Nominal }}$

- Heat pump sizing factor: 1.00 and 1.25

These parameters may cover a significative role because of their influence in ensuring the plant to recover rapidly from inconvenient thermal levels taking place after long forced switching off periods.

Moreover, four main control strategies were considered and simulated. They are described below:

- Ref. It is the basic control strategy, consisting in switching on/off the heat pump only basing on the thermal storage temperatures, through on-off command and $5 \mathrm{~K}$ hysteresis. 


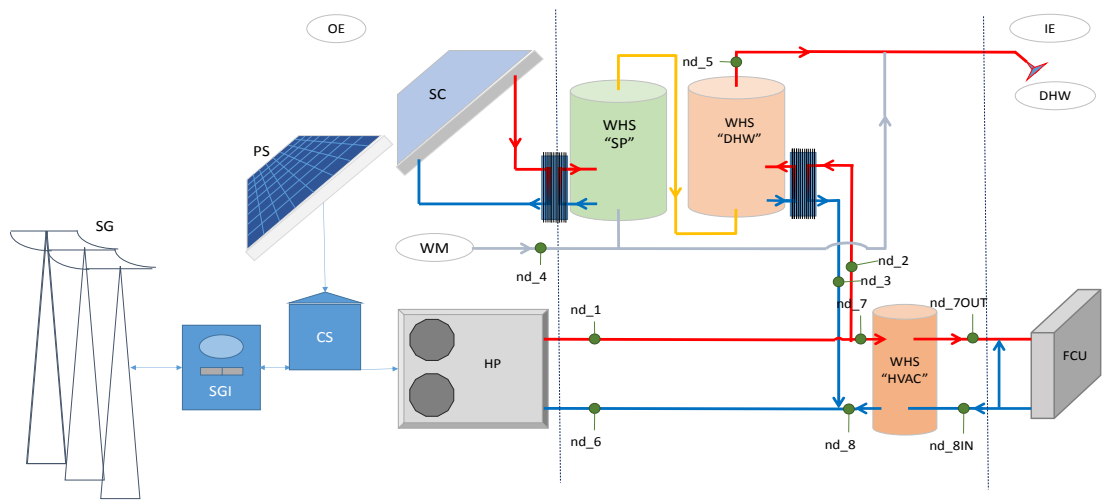

CS: Control System

DHW: Domestic Hot Water

FCU: Fan-Coil Units

HP: Heat Pump

HVAC: Heating, Ventilation and Air-

Conditioning

IE: Indoor Environment

OE: Outdoor Environment
PS: Photovoltaic System

SC: Solar Collectors

SG: Smart Grid

SGI: Smart Grid Interface

SP: Solar Plant

WHS: Water Heat Storage

WM: Water Mains

Figure 5: Scheme of the simulated HVAC system.

- Type A. This control strategy manages heat pump switching on/off basing on the current price of the electricity, through the comparison between the current price of electricity and two threshold values, $\mathrm{C}_{\mathrm{ON}, \mathrm{Max}}$ and $\mathrm{C}_{\mathrm{OFF}, \mathrm{Min}}$ (with $\mathrm{C}_{\mathrm{ON}, \mathrm{Max}}<\mathrm{C}_{\mathrm{OFF}, \mathrm{Min}}$ ), named "maximum electricity price for forced switching on" and "minimum electricity price for forced switching off", and follows the following behaviour: $\mathrm{C}<\mathrm{C}_{\mathrm{ON}, \mathrm{Max}}$ : the heat pump is forced to switch on (command signal equal to 2 );

- $\quad \mathrm{C}>\mathrm{C}_{\mathrm{OFF}, \mathrm{Min}}$ : the heat pump is forced to switch off (command signal equal to 0 ;

- $\mathrm{C}_{\mathrm{ON}, \mathrm{Max}}<\mathrm{C}<\mathrm{C}_{\mathrm{OFF}, \mathrm{Min}}$ : switching on/off the heat pump only depends on heat storage temperatures (command signal equal to 1).

In the frame of this study, values $\mathrm{C}_{\mathrm{ON}, \mathrm{Max}}$ and $\mathrm{C}_{\mathrm{OFF}, \mathrm{Min}}$ are calculated in order to ensure uniform coverage among the three operating conditions described above. The threshold values and consequent relative frequencies of occurrence for each range of action are summarised in Table 1. Due to electricity prices, the heat pump could be kept in stand-by mode for some hours, thus making it difficult to provide proper indoor comfort conditions. As a consequence, a further check is performed by the controller: it forces the heat pump to switch on when the water heat storage temperatures get too far 
$(5 \mathrm{~K})$ from the set-point supply temperatures to heating/cooling or DHW devices.

- $\quad$ Type B. This control strategy manages heat pump switching on/off basing on the ratio of the current electricity price to the maximum price forecasted within the following 12 hours. In detail, the controller calculates this ratio and compares it with two threshold values, $\mathrm{R}_{12 \mathrm{~h}, \mathrm{ON}, \mathrm{Max}}$ and $\mathrm{R}_{12 \mathrm{~h}, \mathrm{OFF}, \mathrm{Min}}$ (with $\mathrm{R}_{12 \mathrm{~h}, \mathrm{ON}, \mathrm{Max}}<\mathrm{R}_{12 \mathrm{~h}, \mathrm{OFF}, \mathrm{Min} \text { ), }}$ named "maximum ratio of electricity price for forced switching on" and "minimum ratio of electricity price for forced switching off" respectively. With the proper variations, the behaviour of the controller is similar to the one described for control strategy Type A, with reference to electricity price ratios instead of mere electricity prices. The threshold values for electricity price ratios and the frequencies of occurrence of the consequent ranges of action are summarised in Table 1. This control strategy implements the check on the water heat storage temperature drift as well, as described for control strategy Type A.

- Type C. This control strategy is mainly based on the monitoring of the PV system generation and of the HVAC system needs. In particular, the heat pump is forced to switch on when the PV system is generating electricity. If the PV system is not generating electricity and the HVAC system is requiring less than $15 \%$ of the heat pump nominal capacity, then the heat pump is switched off. Neutral signal (i.e. equal to 1) is thrown for $\mathrm{C}<\mathrm{C}_{\mathrm{ON}, \mathrm{Max}}$. This control strategy is aimed to increase the self-consumption of the electricity generated by the PV system, thus limiting the influence of the building on the smart grid. In this strategy the check against water heat storage temperature drift was implemented as well.

The control strategies described above are summarised in Table 2.

Table 1: Threshold values and related frequencies of occurrence for each range of action, for control strategies Type A and Type B.

\begin{tabular}{|c|c|c|c|c|c|}
\hline \multirow{2}{*}{$\begin{array}{c}\text { Control } \\
\text { strategy }\end{array}$} & $\begin{array}{c}\text { Threshold value } \\
\text { ON,Max }\end{array}$ & \multicolumn{2}{|c|}{$\begin{array}{c}\text { Threshold value } \\
\text { OFF, Min }\end{array}$} & \multicolumn{3}{|c|}{$\begin{array}{c}\text { Frequencies of occurrence } \\
\text { within the specific range of } \\
\text { action [\%] }\end{array}$} \\
\cline { 4 - 6 } & & & Range 2 & Range 1 & Range 0 \\
\hline $\mathrm{A}$ & $\mathrm{CON}, \mathrm{Max}=67.4 € / \mathrm{MWhEl}$ & $\mathrm{COFF}, \mathrm{Min}=80.5 € / \mathrm{MWhEl}$ & 34 & 34 & 32 \\
\hline $\mathrm{B}$ & $\mathrm{R} 12 \mathrm{~h}, \mathrm{ON}, \mathrm{Max}=0.70$ & $\mathrm{R} 12 \mathrm{~h}, \mathrm{OFF}, \mathrm{Min}=0.83$ & 40 & 24 & 36 \\
\hline
\end{tabular}

In the end, it is noted that the threshold values used during the simulated year were assessed starting from the knowledge of the electricity prices for the whole year. This assumption cannot be followed in actual applications and was a simplification. In actual applications it might be adapted applying the same statistics to the series of electricity prices registered along the 365 days preceding the current one. Anyway, the authors think the assumption used is sufficient for the scope of this analysis. 
Table 2: $\quad$ Scheme of the considered control strategies.

\begin{tabular}{|c|c|c|c|}
\hline $\begin{array}{l}\text { Control } \\
\text { strategy }\end{array}$ & $\begin{array}{c}\text { Forced switching on } \\
\text { (Signal: } 2)\end{array}$ & $\begin{array}{l}\text { Neutral command } \\
\text { (Signal: } 1)\end{array}$ & $\begin{array}{l}\text { Forced switching off } \\
\text { (Signal: } 0)\end{array}$ \\
\hline Ref & - & $\forall \mathrm{C}$ & - \\
\hline Type A & $\mathrm{C}<\mathrm{C}_{\mathrm{ON}, \mathrm{Max}}$ & $\mathrm{C}_{\mathrm{ON}, \mathrm{Max}} \leq \mathrm{C} \leq \mathrm{C}_{\mathrm{OFF}, \mathrm{Min}}$ & $\mathrm{C}>\mathrm{C}_{\mathrm{OFF}, \text { Min }}$ \\
\hline Type B & $\mathrm{R}_{12 \mathrm{~h}}<\mathrm{R}_{12 \mathrm{~h}, \mathrm{ON}, \mathrm{Max}}$ & $\mathrm{R}_{12 \mathrm{~h}, \mathrm{ON}, \mathrm{Max}} \leq \mathrm{R}_{12 \mathrm{~h}} \leq \mathrm{R}_{12 \mathrm{~h}, \mathrm{OFF}, \mathrm{Min}}$ & $\mathrm{R}_{12 \mathrm{~h}}>\mathrm{R}_{12 \mathrm{~h}, \mathrm{OFF}, \mathrm{Min}}$ \\
\hline Type C & $\mathrm{P}_{\mathrm{PS}}>0$ & $\begin{array}{c}\mathrm{P}_{\mathrm{PS}}>0 \\
\wedge \\
\mathrm{P}_{\mathrm{HVAC}}>\hat{\mathrm{P}}_{\mathrm{HVAC}, \mathrm{Nom}} \\
\wedge \\
\mathrm{C}<\mathrm{C}_{\mathrm{ON}, \mathrm{Max}} \\
\end{array}$ & $\begin{array}{c}\mathrm{P}_{\mathrm{PS}}>0 \\
\wedge \\
\mathrm{P}_{\mathrm{HVAC}}<\mathrm{P}_{\mathrm{HVAC}, \text { Nom }}\end{array}$ \\
\hline
\end{tabular}

\section{Results and discussion}

Coupling EnergyPlus and NXT made it possible to get a detailed description of the performance of HVAC systems assisted by photovoltaic systems, here including issues depending on sizing parameters and control strategies.

Advantages and issues related to the examined control strategies are shown in the next pages.

At first, the main data about yearly electricity consumption and generation are shown, in terms of electric energy generated/consumed per floor square meter and year, with weather conditions referring to Milan in 2012. In this regard, Figure 6 shows the PV system is sized to provide about $75 \%$ of the electricity needed by the heat pump to operate during the simulated year. Figure 6(b) shows control strategy Type $\mathrm{C}$ achieves lower energy consumptions in heating and DHW preparation due to high operation frequency during midday hours, when outdoor temperatures are higher, hence even COPs. Figure 6(b) does not show any relevant variation in energy consumption consequent to water heat storage and heat pump sizes. Just a little increase in energy consumption takes place when increasing the

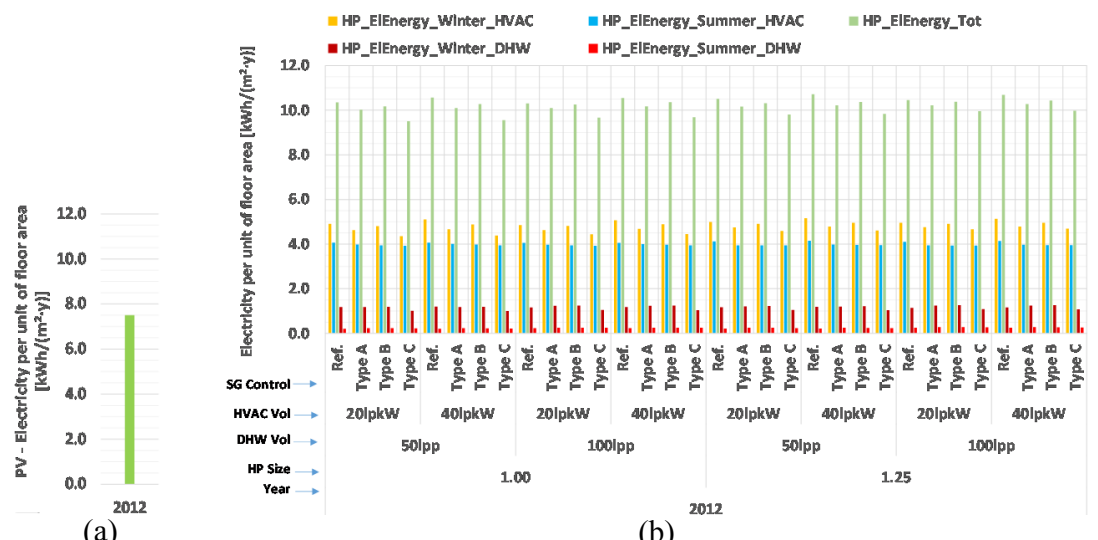

Figure 6: Electricity generated by the simulated photovoltaic system (a) and consumed by the heat pump in heating/cooling and domestic hot water preparation (b). 
size of the water storages, and it comes from the increase of thermal losses through the larger area of the water storage envelope. As a consequence, in the following economical analysis, a lower amount of configurations will be considered in the results discussion, for the sake of simplicity. In particular, results referred to HVAC water heat storage volume equal to $201 / \mathrm{kW}$ will be omitted, thus limiting the analysis to option $40 \mathrm{l} / \mathrm{kW}$.

Figures 7 and 8 are aimed at the evaluation of the cost effectiveness allowed by each control strategy. In particular, Figure 7 shows the difference in yearly costs

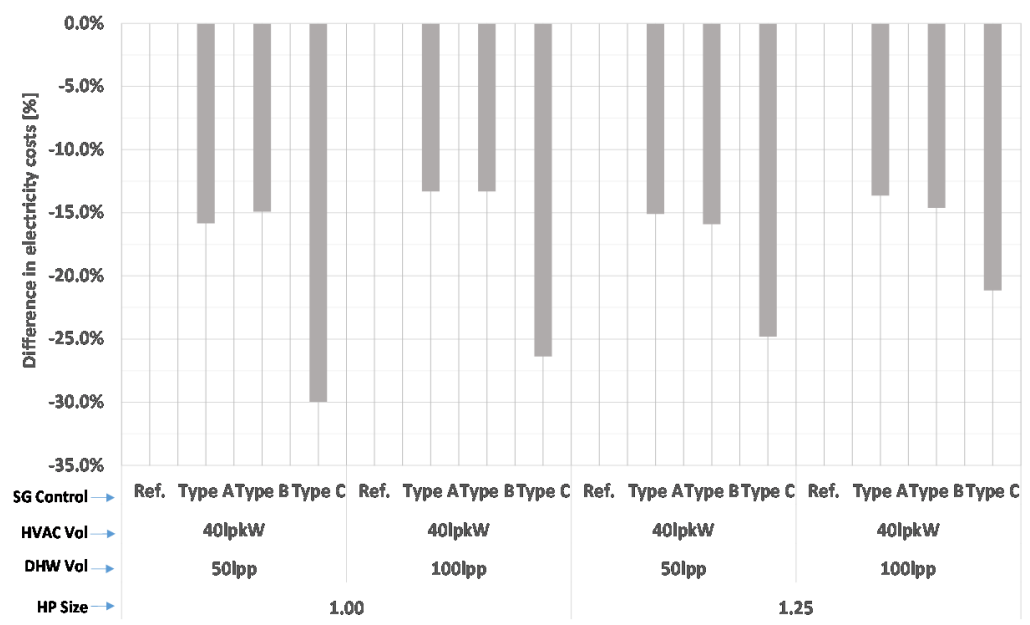

Figure 7: Difference in yearly operation costs in terms of percentage, depending on the control strategy.

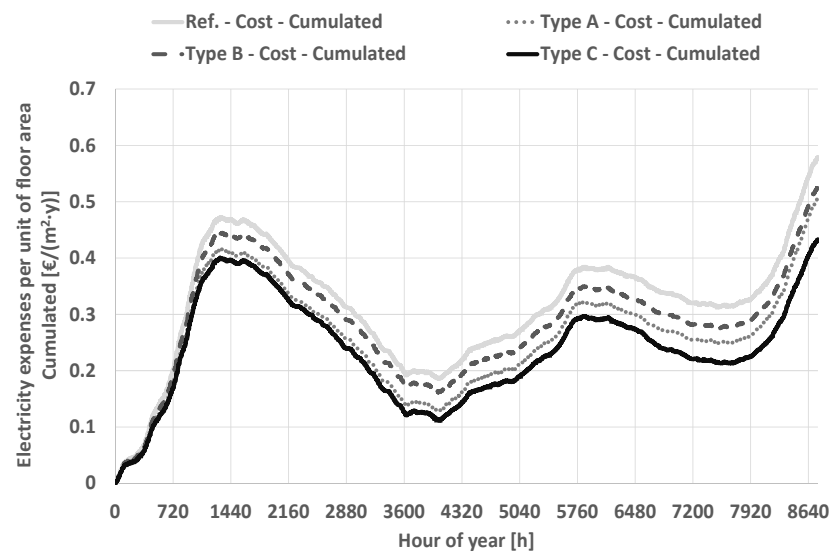

Figure 8: Operation costs in terms of cumulated cash flow along year 2012 for an exemplificative HVAC system configuration, depending on the control strategy. 
between the considered control strategies and the reference one, in terms of percentage for each HVAC system configuration. It shows that the highest cost effectiveness comes with control strategy Type C, as shown in detail in Figure 8, illustrating the cumulated cash flow in a year for a specific HVAC system configuration, depending on the control strategy. These economical evaluations were performed assigning actual hourly electricity prices to related exported/imported electricity.

\section{Conclusions}

This paper showed how control strategies fitted for smart grids and dynamic pricedriven electricity markets may perform from the economic point of view. For this purpose, prices actually defined in Italy in 2012 were considered as well as simultaneous weather conditions, and detailed building energy simulation tools were used. In the simulations performed, the heat pump was used both for heating/cooling and for DHW preparation, coupled with a solar plant and a photovoltaic system.

The simulations performed showed that adequate control strategies make it possible to achieve relevant money savings and ensure good comfort levels as well. The simulations performed showed the best results may be achieved switching on/off the heat pump basing on the PV electric power generation and on the simultaneous heating/cooling loads and electricity prices.

\section{Nomenclature}

\begin{tabular}{|l|l|}
\hline $\begin{array}{l}\text { Symbol } \\
\mathrm{C}\end{array}$ & $\begin{array}{l}\text { Definition, Unit } \\
\text { Price of electricity, } € / \mathrm{MWh}\end{array}$ \\
\hline $\mathrm{En}$ & Energy [kWh or MWh] \\
\hline $\mathrm{P}$ & Power or capacity generated/consumed/exchanged, W \\
\hline $\mathrm{R}$ & Electricity price ratio, adim. \\
\hline Subscripts & Definition \\
\hline $12 \mathrm{~h}$ & Within next 12 hours \\
\hline Dem & Demand of electricity \\
\hline El & Electric \\
\hline HP & Referred to the heat pump \\
\hline Lim & Limited \\
\hline Nom & Nominal \\
\hline OFF & Referred to forced switching off \\
\hline Off & Offer of electricity \\
\hline ON & Referred to forced switching on \\
\hline Max & Maximum \\
\hline Min & Minimum \\
\hline PS & Referred to the photovoltaic system \\
\hline
\end{tabular}




\begin{tabular}{|l|l|}
\hline Abbreviations & Definition \\
\hline DHW & Domestic Hot Water \\
\hline HVAC & Heating, Ventilation and Air Conditioning \\
\hline
\end{tabular}

\section{References}

[1] ENEA - Agenzia nazionale per le nuove tecnologie, l'energia e lo sviluppo sostenibile. 2013. Rapporto annuale efficienza energetica 2012. ISBN 97888-8286-300-5.

[2] De Martinis U., Lucia F., Crisci L. 2012. Mercato italiano dell'energia elettrica - Oltre la Grid Parity, Enmoveme.

[3] Jorgensen, J.M., Sorensen, S.H., Behnke, K. \& Eriksen, P.B. EcoGrid EU A Prototype for European Smart Grids. Power and Energy Society General Meeting, 2011 IEEE, San Diego, CA (U.S.A.). ISSN: 1944-9925.

[4] Hübner M. \& Prüggler N. Smart Grids Initiatives in Europe - Country Snapshots and Country Fact Sheets. Austrian Federal Ministry for Transport, Innovation and Technology, 2011.

[5] JRC - Scientific and Policy Report. Smart Grid projects in Europe: Lessons learned and current development, 2012.

[6] Delta Energy and Environment. Smart Heat Pumps: Enablers of a Low Carbon Future, 2011.

[7] IEA Heat Pump Programme. IEA HPP Annex 28 - Country report in Switzerland on task 1: System analysis and state of the art in standardization, 2003. 